\title{
EXPERIMENTAL EVALUATION OF THE EFFECTS OF STRUCTURAL CHANGES ON THE VIBRATION PROPERTIES OF CK35 STEEL
}

\author{
Navid Moshtaghi YAZANI* \\ *Department of Mechanical Engineering, University of Tehran, 16th Azar St., Enghelab Sq., Tehran, Iran \\ navid.moshtaghi@ut.ac.ir
}

received 29 January 2021, revised 8 May 2021, accepted 12 May 2021

\begin{abstract}
The microstructure of some components which operate in high-temperature conditions (e.g. boiler components, turbine blades used in gas power plants, jet engines and reactors) is subjected to changes in long run, which leads to a degradation in the mechanical properties of these components and consequently, reduces their lifecycle. Therefore, it is so useful to detect the changes in the microstructure of these parts during their operation, employing an easy, fast and non-destructive method to determine their remaining life. In this study, we evaluate the effects of the microstructural changes on natural frequencies and the damping coefficient of CK35 steel, employing the experimental modal test. We aim to use the method for power plant components, if it has significant effects. To do so, we applied spheroidization heat treatment on CK35 steel samples having a primary structure of ferrite-pearlite for 24 and 48 hours. Then, we carried out the experimental modal test on samples having different metallurgical structures, but with the same dimensions and weights. According to the findings, the spherical ferrite-carbide particles in the ferrite structure increase the natural frequencies and damping coefficient. These tests show that the structural changes in this type of steel result in slight changes in the values of natural frequencies; however, it significantly changes the damping frequencies.
\end{abstract}

Keywords: microstructure, spheroidization heat treatment, modal analysis, natural frequency, damping

\section{INTRODUCTION}

Changes in metal microstructures can influence their macroscopic properties. A change in microstructure can be the formation of a new phase in the metal matrix, a change in the size of a grain or the size of a phase and/or sediment particles in a metal matrix. Some of the mechanical properties including toughness, yield strength and elasticity modulus, as well as some vibration properties such as natural frequencies and damping coefficient, may be influenced by changes in the metal microstructure. Numerous studies have been carried out regarding the influences of microstructure on the mechanical properties of metals. For example, Zieliński et al. (2017) evaluated the effects of ageing heat treatment on T24 steel microstructure and its mechanical properties. They concluded that as the ageing duration and its temperature increase, the steel mechanical properties degrade, which can be attributed to some reasons including the metal matrix recovery, removing the layers of bainitic structure, an increase in the size of carbides M23C6, as well as the formation of secondary sediments of M2C and M6C3 in the metal matrix. Carneiro et al. (2018) addressed the influence of ageing in the microstructural aspects in an A356 alloy and its impact in the static and damping. This study analyses the role of $\mathrm{T} 6$ heat treatments in the overall microstructure of A356 poured in ceramic block, associating the morphology transformations with the internal mechanisms that enhance yield strength and reduce damping. They suggested that these variables display an inverse proportionality and a linear model is determined for the design of alloys with tailored yield/damping by the use of different artificial ageing times. Carneiro, V.H., and Puga, $H$. (2018) investigated the influence of solution treatment in the microstructural aspects (e.g. eutectic Si spheroidization) in an
A356 alloy and its impact in the static and damping. Their findings owing to eutectic Si coarsening/spheroidization, Mg2Si/Tr-phase dissolution and a-Al solution strengthening, the solution treatment can enhance both static (yield strength) and dynamic (damping ratio) mechanical properties. As well, several other studies can be found in the field of microstructure influences on the mechanical properties of a metal (Bhardwaj et al., 2021; Diehl et al., 2010; Yamada et al., 2006; Liu et al, 2012; Ghorbanhosseini et al., 2020; Korznikova et al., 2020; Wang et al., 2020; Ghosh et al., 2008).

Hamisi et al. (2018) studied the ageing effects on the mechanical and vibration properties of SA516 carbide steels. They suggested that an increase in the ageing duration can degrade the samples' mechanical properties, reduce their natural frequencies and increase the samples damping properties. Tsai, M. H. et al. (2011) addressed the effects of ageing heat treatment on vibration properties of an $\mathrm{Mg}-\mathrm{Zr}$ alloy. They concluded that as the ageing heat-treatment temperature increases, some twin structures are formed in the alloy matrix, which plays a significant role in changing the samples' damping coefficients. El-Morsy, A. W., \& Farahat, A. I (2015) investigated the effects of ageing heat-treatment duration on the damping of Mg-6Al-1 $\mathrm{Zn}$ alloy. They found that increasing the ageing duration, the number of settled phases also increases. They showed that the ageing of this alloy up to 34 hours can increase its damping properties, and the damping value decreases, as the ageing duration increase. Carneiro, V.H., and Puga, H. (2019) studied the impact of microstructure and T6 heat treatment on Young's modulus and internal friction. Moreover, some other studies have addressed the influences of microstructure on metal vibration parameters (Lin et al., 2002; Limarga et al., 2007; Cai et al., 2005). 
As mentioned earlier, the changes in metal structures may influence their mechanical and vibration properties. Therefore, by employing some methods to investigate the mechanical and vibration properties of metals, it is possible to find the changes in the data profile of their structure, without a need to use metallography methods. In this study, we employed a modal nondestructive test to find the data profile of metal structures. In other words, using a modal test and analysing its results, rather than employing destructive tests such as metallography and hardness measurement tests, can one discover the changes in data profiles of metal structures that operate in superheated conditions. Therefore, we chose the CK35 steel having a primary structure of ferrite-pearlite and observed that the maximum changes occurred in its structure, as spheroidization heat treatment applied. It is worth mentioning that we chose this kind of heat-treatment process to induce the maximum changes in the steel structure to conclude that how much the maximum changes in the structure will change the steel vibration properties of the steel. Then, we applied the modal experimental test and hammer test for samples having completely the same dimensions and different structures.

\section{EXPERIMENTAL PROCESSES}

\subsection{Heat treatment}

To study the effects of microstructure changes on the steel vibration properties, employing a heat-treatment process causing a significant change in the structure is considered suitable. In this study, we chose CK35 steel having the primary structure if ferritepearlite. The chemical composition of this steel is shown in Tab. 1, according to optical emission spectrometry test and ref. 21 . The maximum change in ferrite-pearlite structure occurs when the cementite layers in the pearlite phase are dispersed spherically in the ferrite structure, which can be reached by applying the spheroidization heat-treatment process.

As the spheroidization heat-treatment process in the natural mode can be so time-consuming, the process can be much less time-consuming if the primary structure is martensite (Chandler, 1998; Totten, 2006). Therefore, the samples maintained in the furnace at an austenite temperature for enough time (about 1 hour) to reach a complete austenite structure, and immediately they were cooled, so that they reached a martensite structure. Then, the samples were heated at $700^{\circ}$ to reach spherical structure in their matrix, 2 of which for 24 hours and the other 2 for 48 hours (Chandler, 1998). Following, the samples cooled in the furnace.

Tab. 1. Chemical properties of the CK35 steel, weight percentage (\%)

\begin{tabular}{|c|c|c|c|c|}
\hline & $\mathbf{C}$ & $\mathbf{M}$ & $\mathbf{P}$ & $\mathbf{S}$ \\
\hline $\begin{array}{c}\text { Optical emission } \\
\text { spectrometry test }\end{array}$ & 0.34 & 0.621 & 0.0121 & 0.018 \\
\hline Ref. 21 & $0.32-0.38$ & $0.6-0.9$ & $\begin{array}{c}\text { Max. } \\
0.04\end{array}$ & $\begin{array}{c}\text { Max. } \\
0.05\end{array}$ \\
\hline
\end{tabular}

\subsection{Frequency response}

The modal test is an experimental technique to find the modal model for a vibration system. This theory is based on the relation- ship between the vibration response in a certain point of the structure and the excitation at the same point or other points as a response to the excitation frequency. The relationship that is often in a form of a mathematical complex function is called the frequency response function (FRF). The modal test includes the FRF measurements and the structure impact response. In other words, one can easily measure the FRF, exerting a (measured) force at a certain point of the structure, in the absence of other excitement forces, and measuring the vibration response in one or more points of the structure [24].

In this study, we employed the modal test, as well as the hammer test, by the help of which can one obtain the natural frequencies and damping values of the samples. As the samples' natural frequencies and the damping values are compared in this study, the samples should have as the same dimensions and weights as possible to investigate the effects of microstructure changes on the steel vibration properties. Fig. 1 shows the prepared samples for the test. The sample weights are equal to $633.33 \pm 0.02 \mathrm{~g}$, and their dimensions are the same in a $0.01-\mathrm{mm}$ precision range (Fig. 1).

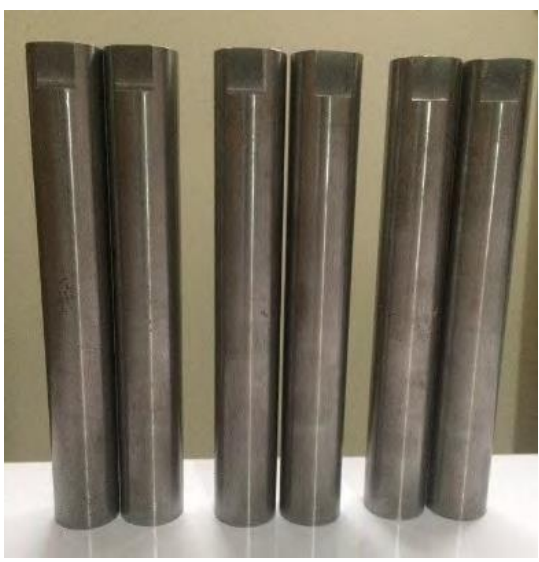

Fig. 1. Prepared samples for the modal test

Fig. 2 and Fig. 3 shows how this test is carried out and the tools used in the test. The test applied to samples in free-free boundary conditions. To obtain the samples' vibration properties, their frequency response (FRF) should be explored. To this end, a hammer (Type 8202 Bruel \& Kjae) and a piezoelectric accelerometer employed to excite the samples and to measure their responses, respectively. It should be mentioned that the test was carried out in several different points of the samples. As well, applying 10 hits and averaging the responses, each sample frequency response was obtained. a)

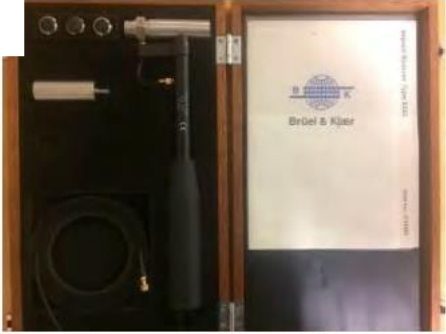

b)

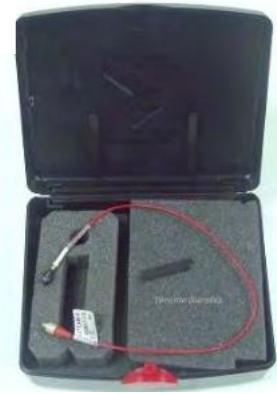

Fig. 2. Used tools in the modal test: a) Hammer and its accessories; b) piezoelectric accelerometer 


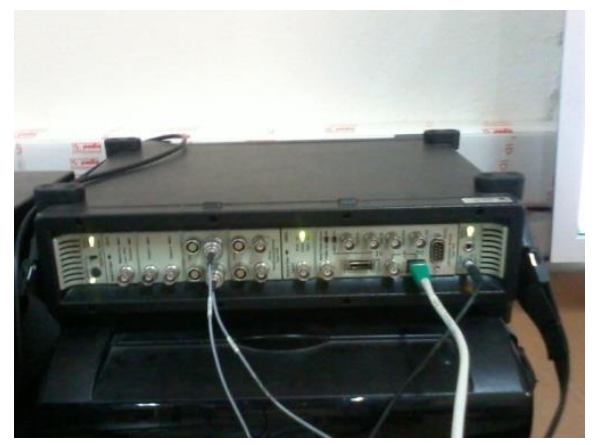

Fig. 3 Four-channel data collection model, model $3560 \mathrm{c}$

Then, the damping coefficients were obtained, using frequency responses and employing the peak-peaking technique (halfpower bandwidth) (Fig. 4). In this technique, the damping coefficient can be conveniently calculated, using eq. 1 . In this method, the maximum amplitude (i.e. $\left.\left|\alpha \mathrm{W}_{\mathrm{r}}\right|\right)$ that is related to the natural frequencies of each vibration mode of the system is first obtained, and then the frequencies $\left(\mathrm{W}_{\mathrm{b}}, \mathrm{W}_{\mathrm{a}}\right)$ are chosen at both sides of the resonance peak having an amplitude of $\frac{\left|\alpha \mathrm{W}_{\mathrm{r}}\right|}{2}$.

The damping loss factor is obtained from eq. 1, according to the peak resonance width (Fu, Z. F., \& He, J, 2001).

$\eta_{\mathrm{r}}=\frac{\mathrm{w}_{\mathrm{b}}^{2}-\mathrm{w}_{\mathrm{a}}^{2}}{2 \mathrm{w}_{\mathrm{r}}^{2}}=\frac{\mathrm{w}_{\mathrm{b}}-\mathrm{w}_{\mathrm{a}}}{\mathrm{w}_{\mathrm{r}}}$

where $\mathrm{W}_{\mathrm{r}}$ is the maximum frequency of the diagram amplitude, and $W_{r}$ and $W_{b}$ are the frequencies at both sides of the peak resonance.
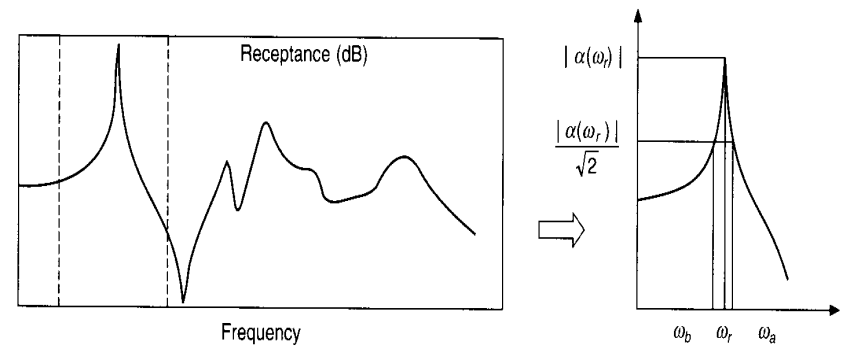

Fig. 4. Peak-peaking technique to calculate the damping loss factor

\subsection{Tensile test}

To study the effects of heat-treatment process on the steel elasticity modulus - that is considered as an important parameter influencing the natural frequency value - some samples were prepared according to ASTM E8/E8M. The gauge length and diameters of these samples were 25 and $6 \mathrm{~mm}$, respectively, that is categorized as sub-size samples according to the standard.

\section{FINDINGS AND DISCUSSIONS}

\subsection{Microstructure}

Fig. 5a shows the steel microstructure before applying the spheroidization heat-treatment process. As can be seen, the steel structure consists of ferrite and pearlite phases; the ferrite phase is shown in white, while the pearlite phase is brown. Fig. $5 b$ and $5 c$ shows the steel microstructure after spheroidization heat treatment after 24 hours and 48 hours respectively. As can be observed in these figures, after applying the spheroidization heattreatment process, the cementite phases which are placed in the pearlite structure in a layered manner will be distributed spherically and dispersedly in the ferrite matrix. According to Fig. 5b and $5 c$, one can conclude that there exists no significant difference between the samples heat treated for 24 hours and those processed for 48 hours. In other words, it seems that once the samples are heat treated for 24 hours, the cementite phase sizes are saturated, and increasing the heat-treatment time incurs no significant changes in the size of these phases. Therefore, according to the microstructures shown in the figures, it seems that the results of the modal test and the tensile test that was applied to samples heat treated for 24 and 48 hours have no significant differences. a)

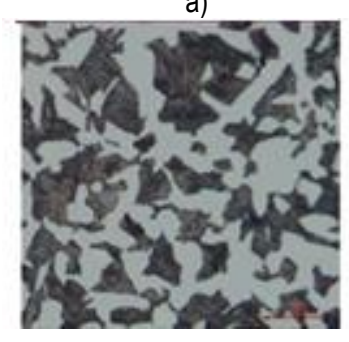

b)
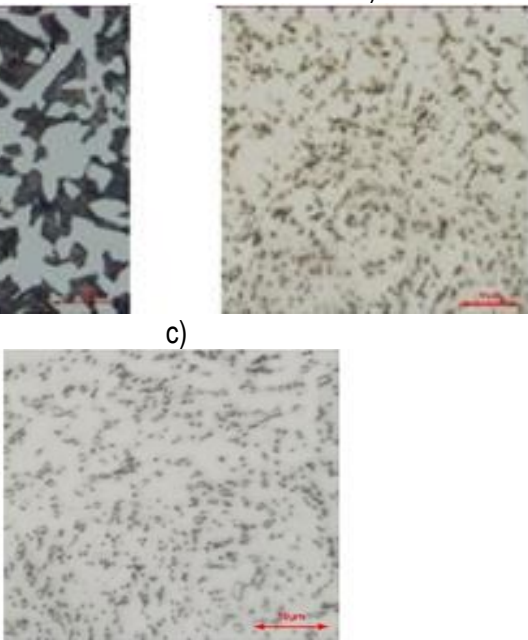

Fig. 5. Microstructures: (a) the sample before applying heat-treatment process, with a magnification factor of $200 \times$, Nital etch solution $3 \%$; (b) heat-treated sample for 24 hours with a magnification factor of $1000 \times$, Picral etch solution, 4\%; and (c) heat-treated sample for 48 hours with a magnification factor of $1000 x$, Picral etch solution, $4 \%$

\subsection{Results of the modal and tensile tests}

As mentioned before, 2 samples of each heat-treatment process were prepared for the modal test. Figure 6 shows the obtained frequency response, following the sample excitation by the hammer. The results of the modal test are summarized in Table 2. It should be noted that these results are related to the case where the sensor installation and the hammer hit are both placed in the middle of the samples. According to the modal test results, it is observed that following the spheroidization process, the natural frequencies and the damping loss factor of the two modes of the first and second vibrations are increased. In other words, the dispersion of cementite particles within the ferrite matrix increases the natural frequencies, as well as damping loss factor. Moreover, the results show that although structural changes incur slight changes in natural frequencies, the phenomenon causes significant changes in the damping loss factor, so that the damping loss factor increases at least $14 \%$, with a change in ferrite-pearlite structure to a spheroidized structure. 


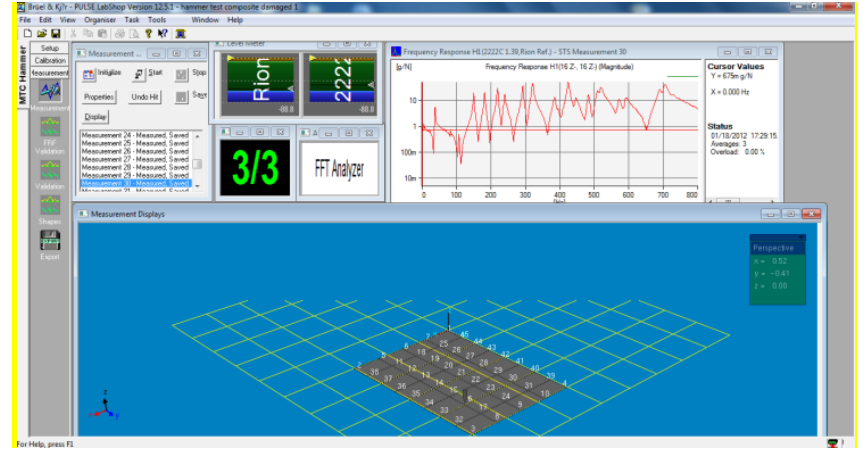

Fig. 6. Obtained frequency response following the sample excitation

Tab. 2. Results of modal test

\begin{tabular}{|c|c|c|c|c|}
\hline \multirow{2}{*}{ Sample } & \multicolumn{2}{|c|}{$\begin{array}{c}\text { Natural frequency } \\
\text { (Hz) }\end{array}$} & \multicolumn{2}{c|}{$\begin{array}{c}\text { Damping loss factor } \\
\text { (percentage of difference } \\
\text { compared to the non- } \\
\text { heat-treated sample) }\end{array}$} \\
\cline { 2 - 5 } & $\begin{array}{c}\text { First } \\
\text { mode }\end{array}$ & $\begin{array}{c}\text { Second } \\
\text { mode }\end{array}$ & First mode & $\begin{array}{c}\text { Second } \\
\text { mode }\end{array}$ \\
\hline $\begin{array}{c}\text { Non-heat } \\
\text { treated }\end{array}$ & 3722 & 9424 & 0.00204 & 0.00328 \\
\hline $\begin{array}{c}\text { Heat treated for } \\
\text { 24 hours }\end{array}$ & 3735 & 9447 & $\begin{array}{c}0.00257 \\
(+0.14 \%)\end{array}$ & $\begin{array}{c}0.00371 \\
(+2.51 \%)\end{array}$ \\
\hline $\begin{array}{c}\text { Heat treated for } \\
\text { 48 hours }\end{array}$ & 3734 & 9448 & $\begin{array}{c}0.00280 \\
(+0.15 \%)\end{array}$ & $\begin{array}{c}0.00282 \\
(+2.14 \%)\end{array}$ \\
\hline
\end{tabular}

One can refer to the results of the tensile test (Table 3 ) to find a reason for the increase in natural frequencies. According to the results, the distribution of cementite particles in the ferrite phase causes the elasticity modulus to increase, which in turn leads to an increase in the natural frequency. As well, the spheroidization process can increase the phase continuity that causes an increase in damping (Visnapuu et al., 1987).

Tab. 3. Results of the tensile test

\begin{tabular}{|c|c|}
\hline Sample & Elasticity modulus \\
\hline Non-heat treated & 204.80 \\
\hline Heat treated for 24 hours & 208.50 \\
\hline Heat treated for 48 hours & 207.29 \\
\hline
\end{tabular}

According to the results of the modal and the tensile tests, one can see that increasing the heat-treatment duration from 24 hours to 48 hours, the natural frequencies, damping loss factor and the elasticity modulus don't change significantly. According to the microstructure similarities between samples that were heat treated for 24 hours and 48 hours, these results can be predictable.

\section{CONCLUSION}

This study has been carried out to find whether it is possible to use the modal test as a non-destructive test to discover the changes in metal microstructures. The experimental test results showed that the dispersion of carbide phases within the ferrite matrix increases the natural frequencies and damping loss factors. According to the results of the modal test, slight changes in the microstructure may lead to slight changes in natural frequen- cy, while changing the structure incurs no significant changes in the damping loss factor value. According to findings, one can see that microstructure changes in this steel cause the vibration parameters to change. Therefore, the modal test - which is a cheap and fast method to obtain a system vibration data - can be employed as a non-destructive test to detect the structural changes in components that are operated in superheated conditions.

\section{REFERENCES}

1. Abedrabbo N., Pourboghrat F., Carsley J. (2006), Forming of AA5182-O and AA5754-O at elevated temperatures using coupled thermo-mechanical finite element models, Internatio-nal Journal of Plasticity, 23, 841-875.

2. Bandara, C. S., Siriwardane, S. .C., Dissanayake, U. I., \& Dissanayake, R. (2016), Full range S-N curves for fatigue life evaluation of steels using hardness measurements, International journal Journal of fatigueFatigue, 82, 325-331.

3. Akhil Bhardwaj A., Naishadh Gohil N., Amit Kumar Gupta A.K., S.S. Satheesh KumarK.S.S. (2021), An experimental investigation on the influence of elevated-temperature constrained groove pressing on the microstructure, mechanical properties and hardening behaviour of Ti6Al4V alloy, Materials Science and Engineering, Volume 802., 20 January 2021, 140651

4. Bolkowski S., Stabrowski M., Skoczylas J., Sroka J., Sikora J., Wincenciak S. (1993), Komputerowe metody analizy pola elektromagnetycznego, WNT, Warszawa.

5. Cai, W., Lu, X. L., \& Zhao, L. C. (2005), Damping behavior of TiNi-based shape memory alloys, Materials Science and Engineering: A, 394 (1-2), 78-82.

6. V.H. Carneiro V.H., H. Puga. H. (2018), Solution Treatment Enhances Both Static and Damping Properties of Al-Si-Mg alloys, Metall Mater Trans, 5942-5945.

7. V.H. Carneiro V.H., H. Puga. H. (2019), T6 Heat Treatment Impact on the Random Frequency Vibration Stress of Al-Si-Mg Alloys. Met. Mater. Int, 25, 880-887.

8. V.H. Carneiro V.H., H. Puga H., J. Meireles, J. (2018), Heat treatment as a route to tailor the yield-damping properties in A356 alloys, Materials Science and Engineering 729, 1-8.

9. Chandler, H. (Ed.). (1994), Heat treater's guide: practices and procedures for irons and steels, ASM international.

10. Diehl, A., Engel, U. \&, Geiger, M. (2010), Influence of microstructure on the mechanical properties and the forming behaviour of very thin metal foils, Int J Adv Manuf Technol, 47, 57-61

11. El-Morsy, A. W., \& Farahat, A. I. (2015), Effect of aging treatment on the damping capacity and mechanical properties of Mg-6al-1Zn alloy, The Scientific World Journal, Volume 2015 ,pages 1-8, https://doi.org/10.1155/2015/170458

12. Fu, Z. F., \& He, J. (2001), Modal analysis, Elsevier.

13. S. Ghorbanhosseini S, ., F. Fereshteh-Saniee F., A. Sonboli. A. (2020), An experimental investigation on the influence of elevatedtemperature constrained groove pressing on the microstructure, mechanical properties, anisotropy and texture of $2024 \mathrm{Al}$ sheets, Journal of Alloys and Compounds, 817, 152763

14. Ghosh, S. K., \& Mondal, S. (2008), High temperature ageing behaviour of a duplex stainless steel, Materials Characterization, 59(12),

1776-1783.

15. Goshima T., Hanson M.T., Keer L.M. (1990), Three-dimensional analysis of thermal effects on surface crack propagation in rolling contact, Journal of Thermal Stresses, Vol. 13, 237-261.

16. Hamisi, M.,Torshizi, S. (2018), Experimental Study of Aging Effect on Mechanical and Vibrational Properties on Carbon Steel Sa516, Modares Mechanical Engineering, Vol 18, 50-55.

17. Korznikova, G., Kabirov, R., Nazarov, K. et al. (2020), Influence of Constrained High-Pressure Torsion on Microstructure and 
Mechanical Properties of an Aluminum-Based Metal Matrix Composite, JOM, (72), 2898-2911.

18. Limarga, A. M., Duong, T. L., Gregori, G., \& Clarke, D. R. (2007), High temperature vibration damping of thermal barrier coating materials. Surface and Coatings Technology, 202(4-7), 693697.

19. Lin, S. C., Lui, T. S., Chen, L. H., \& Song, J. M. (2002), Effect of pearlite on the vibration-fracture behavior of spheroidal graphite cast irons under resonantconditions, Metallurgical and Materials Transactions A, 33(8), 2623-2634.

20. Shaojun LiuL., Qunying HuangH., Lei PengP., Yanfen LiL., Chunjing Li. (2012), Microstructure and its influence on mechanical properties of CLAM stee, Fusion Engineering and Design: A, 89(9), 1628-1632.

21. Totten, G. E. (2006), Steel Heat Treatment Handbook, 2 Volume Set. CRC press.

22. Tsai, M. H., Chen, M. S., Lin, L. H., Lin, M. H., Wu, C. Z., Ou, K. L., \& Yu, C. H. (2011), Effect of heat treatment on the microstructures and damping properties of biomedical $\mathrm{Mg}-\mathrm{Zr}$ alloy, Journal of Alloys and Compounds, 509(3), 813-819.
23. Visnapuu, A., Nash, R. W., \& Turner, P. C. (1987), "Damping properties of elected steels and cast irons., UNITED STATES DEPARTMENT OF THE INTERIOR

24. Xiao-Feng Wang X-F, Tong-Ya Shi T-Y, He-Bin Wang H-B, SongZe Zhou S-Z, Wen-Fei Peng W-F, Yong-Gang Wang. Y-G (2020), Effects of strain rate on mechanical properties, microstructure and texture of $\mathrm{Al}-\mathrm{Mg}-\mathrm{Si}-\mathrm{Cu}$ alloy under tensile loading, , Transactions of Nonferrous Metals Society of China, 30(1), 27-40.

25. Yamada, T., Okano, S., \& Kuwano, H. (2006), Mechanical property andmicrostructural change by thermal aging of SCS14A cast duplex stainless steel, Journal of Nuclear Materials, 350(1), 47-55.

26. Zhang, Z., Zeng, X., \& Ding, W. (2005), The influence of heat treatment on damping response of AZ91D magnesium alloy, Materials Science and Engineering: A, 392(1-2), 150-155.

27. Zieliński, A., Golański, G., \& Sroka, M. (2017), Influence of longterm ageing on the microstructure and mechanical properties of T24 steel, Materials Science and Engineering: A, 682, 664-672. 